\title{
XPS Investigations of Ruthenium Deposited onto Representative Inner Surfaces of Nuclear Reactor Containment Buildings
}

\author{
C. Mun ${ }^{1}$, J J . Ehrhardt ${ }^{2}$, J . Lambert ${ }^{2}$, C. Madic ${ }^{3}$ \\ ${ }^{1}$ Institut de Radioprotection et de Sûreté Nucléaire (IRSN), Direction de la Prévention des \\ Accidents Majeurs (DPAM), Centre de Cadarache, BP3 - 13115 Saint-Paul-lez-Durance (France) \\ Mail to: christian.mun@irsn.fr ${ }^{\times}$ \\ ${ }^{2}$ Laboratoire de Chimie Physique et Microbiologie pour l'Environnement (LCPME) UMR 7564 \\ CNRS-Nancy University - 405, rue de Vandoeuvre 54600 Villers-lès-Nancy (France) \\ Mail to: ehrhardt@lcpe.cnrs-nancy.fr \\ ${ }^{3}$ Commissariat à l'Energie Atomique (CEA), Direction de l'Energie Nucléaire, Centre de \\ Saclay, 91191 Gif-sur-Yvette Cedex - France \\ Mail to: charles.madic@cea.fr
}

\section{ABSTRACT}

In the case of a hypothetical severe accident in a nuclear power plant, interactions of gaseous $\mathrm{RuO}_{4}$ with reactor containment building surfaces (stainless steel and epoxy paint) could possibly lead to a black Ru-containing deposit on these surfaces. Some scenarios include the possibility of formation of highly radiotoxic $\mathrm{RuO}_{4}(\mathrm{~g})$ by the interactions of these deposits with the oxidising medium induced by air radiolysis, in the reactor containment building, and consequently dispersion of this species. Therefore, the accurate determination of the chemical nature of ruthenium in the deposits is of the high importance for safety studies. An experiment was designed to model the interactions of $\mathrm{RuO}_{4}(\mathrm{~g})$ with samples of stainless steel and of steel covered with epoxy paint. Then, these deposits have been carefully characterised by scanning electron microscopy (SEM/EDS), electron probe microanalysis (EPMA) and X-ray photoelectron spectroscopy (XPS). The analysis by XPS of $\mathrm{Ru}$ deposits formed by interaction of $\mathrm{RuO}_{4}(\mathrm{~g})$, revealed that the ruthenium is likely to be in the IV oxidation state, as the shapes of the Ru3d core levels are very similar with those observed on the $\mathrm{RuO}_{2}, \mathrm{xH}_{2} \mathrm{O}$ reference powder sample. The analysis of $01 \mathrm{~s}$ peaks indicates a large component attributed to the hydroxyl functional groups. From these results, it was concluded that Ru was present on the surface of the deposits as an oxyhydroxide of $\mathrm{Ru}(\mathrm{IV})$. It has also to be pointed out that the presence of "pure" $\mathrm{RuO}_{2}$, or of a thin layer of $\mathrm{RuO}_{3}$ or $\mathrm{Ru}_{2} \mathrm{O}_{5}$, coming from the decomposition of $\mathrm{RuO}_{4}$ on the surface of samples of stainless steel and epoxy paint, could be ruled out. These findings will be used for further investigations of the possible revolatilisation phenomena induced by ozone.

PACS codes: $28.41 \mathrm{Te}$ (Safety (fission reactor)), $33.60 \mathrm{Fy}$ (X-ray photoelectron spectroscopy), $82.65+r$ (surface interface chemistry)

Keyword: ruthenium oxides, ruthenium deposit, XPS, ruthenium oxyhydroxides.

\footnotetext{
${ }^{\times}$Corresponding author, E-mail address: christian.mun@irsn.fr
} 


\section{INTRODUCTION}

The study of ruthenium behaviour by the French "Institut de Radioprotection et de Sûreté Nucleaire" in cooperation with the CNRS, is motivated by several factors. Firstly, during nuclear reactor operation, the fission-product ruthenium will accumulate in the fuel. The quantity of ruthenium formed increases with fuel burn-up; moreover, its content is more important in MOX (Mixed Oxides) fuel than in classical $\mathrm{UO}_{2}$ fuel. As a consequence, the ruthenium amount formed in fuel life will continuously rise as utilities continuously optimize fuel performance. Secondly, Ru is a high specific activity fission-product. Finally, besides its ability to form oxide compounds which are very volatile, this fission-product has, in addition to its chemical toxicity [1] [2] [3], a high radiotoxicity, essentially through its isotopes ${ }^{106} \mathrm{Ru}\left(\mathrm{T}_{1 / 2}=369\right.$ days $)$ and ${ }^{103} \mathrm{Ru}\left(\mathrm{T}_{1 / 2}=39.3\right.$ days $)$. During a hypothetical nuclear reactor Severe Accident (SA), significant release of volatile ruthenium species from fuel matrix may occur if the fuel is oxidized, for instance in the case of air ingression in the reactor vessel. Ruthenium can then flow through the reactor coolant system, and finally reach the reactor containment building. Under the containment building thermal-hydraulic conditions, the most stable gaseous species is the ruthenium tetroxide: $\mathrm{RuO}_{4}(\mathrm{~g})$.

$\mathrm{RuO}_{4}(\mathrm{~g})$ has been reported to have a certain affinity for iron oxides [4] [5] and for organic compounds [6] [7]. Therefore, the significant part of surfaces present inside the French PWR (Pressurised Water Reactor) containment buildings may act as an efficient trap for $\mathrm{RuO}_{4}(\mathrm{~g})$ and so has to be considered in terms of reactivity, as ruthenium is able of contaminating these inner surfaces (epoxy paints) and all stainless steel materials (316 L/ $304 \mathrm{~L}$ ). As Ru could be trapped by the surface of these materials, it is believed that it would be present in a chemical form with an oxidation state below 8 .

During a SA, the high dose rate in the containment building, linked to the presence of other fission-products than ruthenium, would induce air radiolysis products, notably ozone which is a strong oxidizing agent. Thus, ruthenium deposited onto inner containment surfaces, may be reoxidised up to $\mathrm{RuO}_{4}$. In order to quantify, and next to understand the mechanism involved in this possible oxidation process, information concerning the Ru deposit are required. This paper presents the results of such an analysis and it constitutes a preliminary step of the study devoted to the Ru revolatilisation phenomena. 
Over the past decade, it has been demonstrated that XPS technique could provide powerful information regarding oxidation state and stoichiometry for ruthenium oxides [8] [9] [10] [11]. Nevertheless, the characterisation by this technique is a very complex subject because Ru3d peaks are overlaid by C1s peaks which come from carbon surface contamination. Argon sputtering treatments could be applied to clean up the surface of the samples, but potential secondary effects such as possible reduction of the oxides have to be considered very carefully.

Concerning interactions between gaseous ruthenium tetroxide and stainless-steel substrates, some discrepancies exist between the different studies in the literature. Many authors [12] [13] [14] agree that ruthenium deposits from $\mathrm{RuO}_{4}(\mathrm{~g})$ consist of $\mathrm{RuO}_{2}$, according to the reaction $\mathrm{RuO}_{4}(\mathrm{~g}) \rightarrow$ $\mathrm{RuO}_{2}(\mathrm{~s})+\mathrm{O}_{2}$. Nevertheless, others have questioned this conclusion. For example Eichler [15] attributed the low temperature deposit domain, at about $400 \mathrm{~K}$, to the formation of $\mathrm{RuO}_{3}(\mathrm{~s})$ in nonequilibrium conditions, even if its existence has not been established. This assumption was also supported by Zimmerman et al. [16] who focused their studies on $\mathrm{RuO}_{4}$ photochemical decomposition onto steel substrates. The existence of ruthenium trioxide in solid form was also mentioned by Kim et al. [17] who provides well characterised XPS spectra. They found a surface layer corresponding to $\mathrm{RuO}_{3}$ on anhydrous $\mathrm{RuO}_{2}(\mathrm{~s})$. Sakurai et al. [18] studied $\mathrm{RuO}_{4}(\mathrm{~g})$ interactions with various surfaces, including stainless steels, at room temperature and low pressure. Contrary to the already quoted hypothesis concerning $\mathrm{RuO}_{4}$ decomposition into $\left(\mathrm{RuO}_{2}+\mathrm{O}_{2}\right)$, they were not able to obtain any experimental evidence about dioxide formation, even if the black colour of the deposit is consistent with $\mathrm{RuO}_{2}$. According to them, the deposit was not $\mathrm{RuO}_{2}$, but a ruthenium tetroxide form modified by the interaction with the metal. In fact a $\mathrm{RuO}_{4}$ molecule is supposed to be linked to another one via peroxide Ru-0-0-Ru bonds. In that case, the black deposit observed would consist of $\left(\mathrm{RuO}_{4}\right)_{\mathrm{n}}$ polymerised with peroxide bonds. It must be noticed that no experimental study of the interaction between gaseous ruthenium tetroxide and paints has been carried out yet.

Therefore, the actual nature of this deposit is not well characterised up to now and this study is devoted to a better understanding of the properties of this over layer. For that purpose coatings of $\mathrm{Ru}$ compounds formed by the interaction of $\mathrm{RuO}_{4}(\mathrm{~g})$ with samples of stainless steel and also of painted steel, have been prepared and characterised. 
In this paper, the experimental set-up dedicated to the generation of crystallised ruthenium tetroxide, and the preparation of the ruthenium coatings, by interaction of $\mathrm{RuO}_{4}(\mathrm{~g})$ onto the specific substrates previously cited, are briefly described. Then, an overview of the surface observations by SEM/EDS, and the results obtained by EPMA are presented. The XPS results of the ruthenium deposit samples surface analysis are presented and discussed.

\section{EXPERIMENTAL}

\subsection{Preparation of samples coated with ruthenium deposit}

Since $\mathrm{RuO}_{4}$ is not commercially available due to its instability, the first step consisted in generating this species as pure as possible, under a crystallised form. The principle of this process is based on the oxidation of $\mathrm{Ru}(\mathrm{III})$ to $\mathrm{Ru}(\mathrm{VIII})$, and then, thanks to its volatility, ruthenium tetroxide is transported as a gas and finally condensed in a liquid nitrogen cold trap. More details can be found in the reference [19].

The deposition of ruthenium coatings onto surfaces of stainless steel and painted steel followed the procedure described hereafter. The $\mathrm{RuO}_{4}$ crystals were sublimated from the condenser reactor. The sublimation of $\mathrm{RuO}_{4}$ usually begins at temperature higher than $7^{\circ} \mathrm{C}$ [7] [20]. Then, a

dry air flow transported ruthenium tetroxide vapours through a glass line to a temperature controlled reactor, simulating the containment building (called "Containment Reactor" or CR). Previously, a surface sample was placed inside the CR.

The dimensions of the steel samples were $8.5 \mathrm{~mm} \times 8 \mathrm{~mm} \times 5 \mathrm{~mm}$ (thickness), and $13.3 \mathrm{~mm} \times$ $10 \mathrm{~mm} \times 5 \mathrm{~mm}$ (thickness) for the painted samples, in order to be close to the containment surfacevolume ratio $(0.35)$. The duration of each adsorption experiment was fixed at 24 hours.

The temperature of the $\mathrm{CR}$ was set to $90^{\circ} \mathrm{C}$, that is representative of the containment temperature during a SA. The pictures of a stainless steel sample, before and after ruthenium interaction, are presented in Figure 1. The characteristic black colour deposit is clearly seen on these pictures. 


\subsection{Surface analysis experimental procedure}

\subsubsection{SEM/EDS and EPMA}

Concerning the analysis by SEM/EDS, the ruthenium deposits were examined by a Jeol 6330F scanning electron microscope equipped with an Oxford Si/Li LED. A X-Ray analyzer coupled to the SEM allows us to perform a semi-quantitative analysis of the sample surfaces. Spectra were analysed using the IMIX/PGT software. We worked without metallization of the sample, and using a low tension (lower than $1.5 \mathrm{keV}$ ).

The aim of EPMA analysis was here to determine the thickness of the Ru layer of the deposits. Indeed, the incident electrons will penetrate the matter on a depth of a few $\mu \mathrm{m}$, and the X-ray radiation emitted into the sample will partially be absorbed by itself, before being emitted again in the vacuum, and finally detected. The emitted intensity I is linked to the generated intensity $I_{0}$ at the depth $\mathrm{x}$, by the following equation: $\mathrm{I}=\mathrm{I}_{0} \mathrm{e}^{-\mu \mathrm{x}}$. We performed several measurements of the intensities ratio with and without a Ru layer, by changing the acceleration tension of the electron beam. Then, we used a model named X-film, developed by Merlet et al. [21], which can fit the curve $I / I_{0}=f(V)$, and finally we obtained the surface mass parameter: $x \rho$.

The steel FeKa line at $6.4 \mathrm{keV}$ was used as the X-ray emission of the substrate. The electron beam acceleration tension ranged between 5 and $30 \mathrm{kV}$. For each tension, 20 measurements were performed on random areas onto the Ru deposit, and then onto the steel substrate.

\subsubsection{XPS}

The XPS analyses were carried out with a Kratos Axis Ultra (Kratos Analytical, UK) spectrometer with a hemispherical energy analyser and using a monochromatic AlK $\alpha$ source (1486.6 $\mathrm{eV})$. As the delay-line detector allows a high count rate the power applied to the X-ray anode was reduced to $90 \mathrm{~W}$ so that the possible $\mathrm{X}$-ray induced degradation of the sample was minimized. The instrument work function was calibrated to give a binding energy (BE) of $83.96 \mathrm{eV}$ for the $\mathrm{Au} 4 \mathrm{f7} / 2$ line for metallic gold and the spectrometer dispersion was adjusted to give a BE of $932.62 \mathrm{eV}$ for $\mathrm{Cu}$ $2 \mathrm{p} 3 / 2$ line for metallic copper.

The samples were attached to the sample holder and then evacuated overnight prior analyses. The pressure in the analysis chamber during XPS analysis was in the low $10^{-9} \mathrm{mbar}$ range. 
All spectra were recorded at a $90^{\circ}$ take-off angle, the analysed area being currently about $700 \mu \mathrm{m}^{2}$. Survey spectra were recorded with $1.0 \mathrm{eV}$ step and $160 \mathrm{eV}$ analyser pass energy and the high resolution regions with $0.05 \mathrm{eV}$ step and $20 \mathrm{eV}$ pass energy (instrumental resolution better than $0.5 \mathrm{eV}$ ). In both cases the hybrid lens mode was employed. Spectra were analysed using the Vision software from Kratos (Vision 2.2.0). A Shirley base line allows the subtraction of the background whereas Gaussian G (60\%) Lorentzian L (40\%) peaks or asymmetrical GL peaks were used for spectral decomposition.

The analysed samples were not prepared in situ in the XPS analysis chamber and the ions sputtering cleaning procedure was only used for metallic Ru on which no artefact would be expected. Therefore, in the process of transferring the $\mathrm{Ru}$ containing deposits from the experimental set-up to the XPS analysis chamber, the samples were inevitably exposed to atmospheric conditions and some surface contamination could not be avoided.

In order to have a basis of consistent standards for Ru chemical environments, some reference samples were analysed in the same conditions as described above. For that purpose, it has been used a ruthenium rod purchased from Goodfellow, an anhydrous ruthenium dioxide powder $\left(\mathrm{RuO}_{2}, 99.95 \%\right.$ metals basis), and an hydrated ruthenium dioxide powder purchased from Alfa Aesar $\left(\mathrm{RuO}_{2}, \mathrm{xH}_{2} \mathrm{O}, 99.99 \%\right.$ metals basis, with typically $\left.\mathrm{x} \approx 2.3\right)$.

\section{RESULTS AND DISCUSSION}

\subsection{SEM/EDS}

Due to the apparent non-uniform Ru deposit layer onto both steel and painted substrates, several analyses were performed in each case. For the stainless steel substrate, SEM micrographs and EDS spectra are presented in Figure 2. The lightest-coloured zones rich in $\mathrm{Fe}, \mathrm{Cr}, \mathrm{Ni}$, also contain $\mathrm{Ru}$, and the brownish colour in particular phases is explained by the presence of more $\mathrm{Ru}$ atoms.

SEM micrographs and EDS spectra for the painted sample are presented in Figure 3. It can be seen that ruthenium deposit was clearly crackled, but it was not the epoxy paint coat because $\mathrm{TiO}_{2}$ is visible in the cracks. Ru is clearly under oxidized form, but since the deposits were not perfectly uniform, like those obtained on stainless steel substrates, we do not know if the measured oxygen does not in fact come from the paint. 
Some micro-pellets are present on the surface, and the EDS analysis revealed that in this case the Ru species seemed to be more oxidized than in the brownish homogenous layer. This point may indicate the presence of a second Ru species. Nevertheless, it must be noted that the non flatness of the surface could lead to intensity differences in the 0 peak.

\subsection{EPMA}

Let us note that initially XRD analysis was planned to characterise the structure of the Ru deposits. For both painted and stainless steel substrates, it appeared that it was really difficult to detect ruthenium, evidencing that the thickness of Ru layer must be very low. Nevertheless, it seemed that the steel Ru XRD diagram was characteristic of an amorphous sample. As previously demonstrated by Mills et al. [22], the difference in the crystallinity between anhydrous and hydrated $\mathrm{RuO}_{2}$, is directly related to the content of water in the sample. Even if the Ru layer thickness was extremely low, we can postulate that the species present could be an hydrated ruthenium form.

Due to the last difficulties to get useful information with XRD experiments, a study using EPMA was performed in order to determine the thickness of Ru layer on specific substrates. The methodology, previously detailed in paragraph 1.2.1, has been applied to determine the thickness of the Ru layer on the stainless-steel sample, but it cannot be used for the painted substrate due to its non conductive character. The experimental mean intensities ratios calculated are reported on the Figure 4.

According to these experimental data, we obtain a surface mass of $0.092 \mathrm{mg} / \mathrm{cm}^{2}$. If we assume that the deposit is made of ruthenium dioxide, the corresponding $\mathrm{RuO}_{2}$ density is 7.05 $\mathrm{g} / \mathrm{cm}^{3}$, therefore the thickness of Ru layer can be deduced to be equal to $0.13 \mu \mathrm{m}$. This value is extremely low and coherent with the XRD observations.

\section{$2.3 X P S$}

\subsubsection{Reference samples}

Three reference samples have been analysed in order to establish a coherent basis of binding energies for ruthenium compounds, namely a $\mathrm{Ru}(0) \mathrm{rod}$, an anhydrous ruthenium dioxide powder and an hydrated ruthenium dioxide powder (see paragraph 1.2.2 for the details). 
For both powders, a tablet was realized with $50 \mathrm{mg}$ of dioxide, using a hydraulic power press delivering a pressure of $8000 \mathrm{psi}$. The diameter of each tablet was $13 \mathrm{~mm}$.

Ruthenium dioxide is the most stable species among the family of the ruthenium oxides. In the bulk phase, $\mathrm{RuO}_{4}$ sublimes from $7^{\circ} \mathrm{C}$. It is well known that $\mathrm{RuO}_{3}$ is only thermodynamically stable at temperature higher than $1300^{\circ} \mathrm{C}$ as a gas, and therefore no reference sample can be studied.

A ruthenium slide, cut in a rod, has been freshly polished before its introduction in the analysis chamber and a short argon sputtering treatment has been applied to clean up its surface.

The Ru3d core level spectrum is presented in Figure 5a. As expected for a metal, an asymmetric line shape $(90 \%$ Lorentzian, $10 \%$ Gaussian, with a ratio of the half width at full height of 0.7 ) gives the best fit for the $3 \mathrm{~d} 3 / 2$ and $3 \mathrm{~d} 5 / 2$ lines processing. The spin-orbit coupling gives rise to a separation of $4.21 \mathrm{eV}$ as usually reported in previous published papers [9] [11]. The Ru3d5/2 is pointed out at a binding energy (BE) of $279.95 \mathrm{eV}$, its FWHM (full width at half maximum) being of $0.72 \mathrm{eV}$. This value of BE is in full agreement with the values cited in a previous paper [9] (including the references included in this paper) ranging between 279.96 and $280.3 \mathrm{eV}$. Within the decomposition procedure applied on the spectrum and presented in Figure 5a, two broad peaks are also necessary for a full fit of the spectrum. These features have been previously observed on Ru thin film cleaned by oxidation at $400^{\circ} \mathrm{C}$ to remove carbon contamination followed by reduction in $\mathrm{H}_{2}$ at $300^{\circ} \mathrm{C}$ [9]. The $\mathrm{BE}$ of $\mathrm{Ru} 3 \mathrm{~d} 5 / 2$ component is located at $281.55 \mathrm{eV}$ leading to an apparent shift is about $1.6 \mathrm{eV}$. The interpretation of these peaks is not clear. A straightforward explanation could be the presence of Ru in a higher oxidation state on the surface or in the sub-surface area. However the very weak signal of oxygen weakens considerably this explanation. The presence of shake-up satellites would certainly be privileged in the interpretation of this complex line shape of $\mathrm{Ru}(0)$. Finally, it has to be noticed that no discernable feature at $284.6 \mathrm{eV}$, where the $\mathrm{C} 1 \mathrm{~s}$ core level peak of adventitious carbon contamination is expected, indicating that the cleaning method used here was very efficient.

The anhydrous $\mathrm{RuO}_{2}$ is an oxide that behaves as a metallic conductor and consequently i) no charge correction was necessary to be applied to the BE scale and, ii) an asymmetric line shape is expected [10]. Some Ar sputtering has been tested for cleaning the surface of this sample, dramatic effects have been observed: peak enlargement and also appearance of a totally unexpected $\mathrm{Ru}(0)$ component. 
Therefore no cleaning attempt was applied and some contamination could certainly be present on the surface. The Ru 3d spectrum is reported on Figure $5 \mathrm{~b}$. It is much more complex and six components were necessary to obtain a fit of good quality. The S-O splitting of the two main peaks is estimated to $4.14 \mathrm{eV}$. The $\mathrm{BE}$ of the Ru $3 \mathrm{~d} 5 / 2$ line is pointed out at $280.77 \mathrm{eV}$ in full agreement with previously reported values in the literature [ref. [9] and literature cited therein], ranging between 280.68 and $281.0 \mathrm{eV}$. Besides these mains peaks, a further doublet was introduced with a shift of $1.45 \mathrm{eV}$. This high binding energy spin-orbit doublet was extensively discussed in a previously published article [10] and has been likely attributed to an unscreened final state, the high binding energy doublet being fully screened. It has to be noticed that the intensity of these satellites compared to the intensity of the main peaks is much higher than in the case of $\mathrm{Ru}(0)$. The nature of these extra peaks is certainly very different. Finally, two peaks located at 284.4 and 288.6 $\mathrm{eV}$ have been attributed to C1s due to carbon contamination of the surface of the sample. The value of $284.4 \mathrm{eV}$ is slightly lower than the expected value for adventitious carbon at $284.6 \mathrm{eV}$, but has been judged quite satisfactory considering the rather complex decomposition procedure. The peak at $288.6 \mathrm{eV}$ could be associated to an oxidised form of carbon, for example carbonates.

It is known that $\mathrm{RuO}_{2}$ behaves as a hygroscopic oxide and a hydrated ruthenium dioxide sample has also been investigated. The Ru3d spectrum is presented on Figure $5 c$, the parameters of decomposition used for the anhydrous $\mathrm{RuO}_{2}$ sample (number of peaks, line shapes, FWHMs, ratio branching) have been used here, allowing only a shift of the overall spectrum and of course of the intensities. The fit is fully satisfactory. The $\mathrm{BE}$ of the $\mathrm{Ru} 3 \mathrm{~d} 5 / 2$ core level is pointed at $282.30 \mathrm{eV}$ on this sample in agreement with the value reported recently on $\mathrm{RuO}_{2}$ prepared by electrochemistry [10]. On this sample, the high binding energy spin-orbit doublet is obviously of higher intensity than on anhydrous $\mathrm{RuO}_{2}$ and the $\mathrm{C} 1 \mathrm{~s}$ line is also pointed at $284.4 \mathrm{eV}$. Interestingly enough is the comparison of the 01s spectra obtained on both reference samples and presented in Figures $7 \mathrm{a}$ and 7b, for $\mathrm{RuO}_{2}$ and $\mathrm{RuO}_{2}, \mathrm{xH}_{2} \mathrm{O}$ respectively.

The decomposition of these 01s peaks has been performed in a classical way, using three components $(\mathrm{BE}=529.45,530.75$ and $532.6 \mathrm{eV})$ attributed tentatively to oxygen atoms in three chemical environments namely: $\mathrm{O}^{2-}, \mathrm{OH}^{-}$and $\mathrm{H}_{2} \mathrm{O}$, associated respectively, to lattice oxygen, hydroxyl groups and water adsorbed on the sample. 
It appears clearly that the "water" component is always rather weak, the samples being characterised in UHV conditions, only a bilayer of water molecules is expected to remain on the surface of the oxide according to the enthalpy of adsorption of water [23]. Furthermore the component at $530.75 \mathrm{eV}$ increases significantly in the hydrated $\mathrm{RuO}_{2}$ sample giving then a strong evidence of a hydroxylation process. Therefore it is believed that the exposure of $\mathrm{RuO}_{2}$ to water is not restricted to a simple hydration process, but results in a chemical reaction producing, at least on the surface, a pseudo oxyhydroxide. Finally, one should notice that the so-called anhydrous $\mathrm{RuO}_{2}$ presents also some surface hydroxylation (Figure 6a), probably due to exposure to the ambient atmosphere prior to the transfer to the analysis chamber.

This analysis into three components presents some similarity with the decomposition proposed by Chan et al. [9], on Ru thin films oxidised under oxygen at atmospheric pressure, but the assignments are quite different. The lower binding energy peak was assigned to oxygen atoms of the lattice whereas the high binding energy component would be related to adsorbed atomic oxygen. This interpretation would not be consistent with the sample preparation used in this study.

In this interpretation of the 01s core level line, two types of oxygen atoms are clearly identified if the contribution of water adsorption is neglected. As expected, the more the oxide is hydrated, the more the intensity of the hydroxyl signal is important, and it has to be recalled that the hydroxyl signal is also clearly observed on the "anhydrous" $\mathrm{RuO}_{2}$ sample. Coming back to the Ru3d spectra observed on the anhydrous and hydrated $\mathrm{RuO}_{2}$, it is clear that the high binding energy spin-orbit doublet behaves the same way than this 01s component. Therefore, a new interpretation of this high binding energy spin-orbit doublet could be the fingerprint of Ru atoms having at least one hydroxyl group as neighbour. In the absence of well characterised oxyhydroxide of Ru(IV), the only way to consolidate this hypothesis would be to perform electronic charge calculations on the Ru atoms in various structural configurations. However, this interesting aim is quite away the scope of the present work.

\subsubsection{Stainless steel samples}

The Ru layers deposited on a piece of stainless steel $(8.5 \times 8 \mathrm{~mm})$ have been analysed by XPS without using the charge neutraliser system. It has been checked that the deposit is rather homogeneous on the whole surface in recording the spectra in various zones of the prepared samples, thanks to the low area of analysis $(700 \mu \mathrm{m})$. 
No significant difference was observed. As the spectra are very similar, only a typical example is presented on Figure 7a (Ru3d spectral area), and 8b (01s zone). The spectra of Ru 3d and 01s have been analysed using the procedure developed for ruthenium dioxide samples presented in the previous section. The shapes of the Ru3d core levels are very similar with that we observed on $\mathrm{RuO}_{2}, \mathrm{xH}_{2} \mathrm{O}$. The $\mathrm{BE}$ of the $\mathrm{Ru} 3 \mathrm{~d} 5 / 2$ level is pointed out at $281.4 \mathrm{eV}$ and on this spectra the C1s line appears to be located at a BE of $284.6 \mathrm{eV}$, with a noticeable higher intensity than on the reference sample. The 01s line is however completely dominated by the hydroxyl component.

\subsubsection{Painted samples}

The Ru layers deposited on a piece of painted steel $(13.3 \times 10 \mathrm{~mm})$ have been analysed by XPS (cf. Figure $8 \mathrm{a}$ and $8 \mathrm{~b}$ ). This kind of sample being a bad conductive material, the use of the charge neutraliser could not be avoided. Therefore, after decomposition of the Ru lines by always the same procedure, the $\mathrm{C} 1 \mathrm{~s}$ line was fixed at $284.6 \mathrm{eV}$, and the coherency of this calibration was checked by the $01 \mathrm{~s}$ signal, the $\mathrm{O}^{2-}$ signal appearing at $529.6 \mathrm{eV}$ as expected.

\subsubsection{XPS discussion}

The XPS results for both Ru layers deposited onto steel and painted samples indicate that the nature of the Ru compounds is identical. These species are in accordance to those detected in the hydrated Ru dioxide reference powder.

The fact that the interaction of $\mathrm{RuO}_{4}$ with both stainless steel and painted substrates yields to the formation of the same species can be understood in considering the ruthenium tetroxide decomposition mechanism previously proposed [27]. Indeed, the results obtained during $\mathrm{RuO}_{4}(\mathrm{~g})$ adsorption experiments on the two specific substrates considered here [27], have demonstrated that mean adsorption kinetic constants were extremely low $\left(\approx 10^{-8} \mathrm{~m} \cdot \mathrm{s}^{-1}\right)$. These values would not be consistent with an efficient adsorption mechanism.

It has been concluded that the decomposition of $\mathrm{RuO}_{4}$ in the gas phase should occurred, and the deposition of non-volatile Ru species, i.e. condensation, was at the origin of the deposition phenomenon. As experimentally observed, the Ru deposit was nearly proportional to the surface area (whatever the nature of the substrate: steel, paints and even glass). 
Although the existence of particular species like ruthenium trioxide was claimed by Kim et al. [17] or Zimmerman et al. [16], to be present as a surface structure defect, this interpretation seems not to be consistent with our experimental results. Indeed, the areas of the two Ru $3 d 5 / 2$ peaks in both states are quite similar (cf. Figure 7a and 8a), which are not really convincing for the presence of a structure defect.

The presence of amorphous ruthenium pentavalent oxide species, $\mathrm{Ru}_{2} \mathrm{O}_{5}$, has been also reported by several authors [24] [25] [5], but this form of $\mathrm{Ru}(\mathrm{V})$ is not really consistent with the presence of $\mathrm{OH}^{-}$hydroxyl groups detected here.

From our point of view, hydroxyl forms of ruthenium dioxide are present in the Ru layers. These ones are the only species which could explain their presence in both ruthenium dioxide powders and Ru deposits samples, and consistent with our experimental observations.

In the literature, little is known about the Ru-O-H system, and particularly quantitative thermochemical experiments are lacking. Let us note that Rard [26] indicated, from the scarce thermodynamic data, that $\mathrm{RuO}_{2}, 2 \mathrm{H}_{2} \mathrm{O}$ and $\mathrm{Ru}(\mathrm{OH})_{3}, \mathrm{H}_{2} \mathrm{O}$ are both believed to be metastable. This kind of hydroxide forms of Ru may also be present in our deposits in equilibrium with the hydrated ruthenium dioxide, but the presence of the +III oxidation state is less convincing. By analogy with $\mathrm{Fe}(\mathrm{III})$ or $\mathrm{Mo}(\mathrm{VI})$ oxide and oxyhydroxide species, it might be expected the existence of $\mathrm{RuO}_{2}(\mathrm{OH})_{2}$, but this species must be ruled out by the lower stability of the $\mathrm{Ru}(\mathrm{VI})$ oxidation state, relative to $\mathrm{Ru}(\mathrm{IV})$ one. Thus, the species $\mathrm{RuO}(\mathrm{OH})_{2}$ (hydrated or not) corresponding to an oxyhydroxide of $\mathrm{Ru}(\mathrm{IV}$ ) seems to be one of the most probable Ru forms in our study. 


\section{CONCLUSIONS}

XPS technique used in this study to characterise ruthenium deposits, provide high sensitivity level rarely achieved, allowing us to determine the $\mathrm{BE}$ and the relative contribution of each component in the decomposition of the 01s peaks or the Ru3d core levels. The presupposed decomposition of $\mathrm{RuO}_{4}$ into final $\mathrm{RuO}_{2}$ on the surface was not experimentally verified. Moreover, the presence of the two "exotic" species: ruthenium trioxide or diruthenium pentavalent oxide, already mentioned by different authors, cannot be confirmed with the present study. Another interpretation is proposed.

The XPS results for Ru layers, whatever the nature of the surface is, show that Ru deposits are identical to the hydrated Ru dioxide reference powder. It can be concluded that the ruthenium species on the surface are in the IV oxidation state. The decomposition of 01s peaks for both stainless steel and painted substrates indicate the predominance of the ruthenium hydroxyl forms, corresponding to oxyhydroxide species of Ru(IV).

Thus, oxyhydroxide of Ru(IV) has to be considered in the oxidation process by ozone in nuclear reactor containment buildings. No thermodynamic data are available for the Ru oxyhydroxide species. Experiments to study the possible Ru revolatilisation phenomena by action of ozone are planned.

\section{ACKNOWLEDGMENTS}

This work was achieved through the financial support of the partners of the International Source-Term Project (ISTP) like “Electricité de France” (EDF), CEA, NRC, PSI...

The authors are thankful to A.Grandjean, for her assistance in the SEM/EDS analysis. C.Duriez and S.Sao Joao are also greatly acknowledged for helpful discussions about EPMA analysis. 


\section{REFERENCES}

[1] M.E. Frazier, T.K. Andrews, B.B. Thompson, M.A. Wincek, Evaluation of toxic effects of heavy metals and chelating agents in VERO cells. Pacific Northwest Laboratory Annual Report. DOE Assist. Secr. Environ. (1977).

[2] B. Szubinska, J.H. Luft, Ruthenium red and violet. III- Fine structure of the plasma membrane and extraneous coats in amoebae (A proteus and chaos chaos). Anat. Rec. 171 (1971) 417-442.

[3] R. Masse, Le ruthénium, les métaux activés. Masson ed. Toxiques Nucléaires. (1982) 112-124.

[4] C. Courtois, Oxydes du ruthénium et piégeage des composés volatils du ruthénium, CEA report BIB-213: Fontenay-aux-roses. (1974).

[5] A. Ortins de Bettencourt, A. Jouan, Volatilité du ruthénium au cours des opérations de vitrification des produits de fission (2ème partie) - Rapport CEA-R-3663 (2): CEN de Fontenayaux-Roses. (1969).

[6] P. Pascal, Nouveau traité de chimie minérale, Tome XIX (1958) 21-171.

[7] E.A. Seddon, K.R. Seddon, The Chemistry of Ruthenium. Monograph 19, ed. E. (Amsterdam): Elsevier (1984).

[8] J.Y. Shen, A. Adnot, S. Kaliaguine, An ESCA study of the interaction of oxygen with the surface of ruthenium. Appl. Surf. Sci. 51( 1991) 47-60.

[9] H.Y.H. Chan, C.G. Takoudis, M.J. Weaver, High pressure oxidation of ruthenium as probed by surface enhanced Raman and X-ray Photoelectron spectroscopies. Journal of Catalysis 172 (1997) 336-345.

[10] H.J. Lewerenz, Oxygen Evolution and Corrosion: XPS Investigation on Ru and $\mathrm{RuO}_{2}$ Electrodes. Surf. Sci. 126 (1983) 463-468.

[11] D. Rochefort, P. Dabo, D. Guay, P.M.A. Sherwood, XPS investigations of thermally prepared $\mathrm{RuO}_{2}$ electrodes in reductive conditions. Electrochem. Acta 48 (2003) 4245-4252.

[12] E.T. Maas, J.M. Longo, Confinement of ruthenium oxides volatilized during nuclear fuels reprocessing. Nuclear Technology 47 (1980) 451-456.

[13] M.J. Holdoway, The volatilisation and deposition of ruthenium dioxide in relation to fingal process. Atomic Energy Research Establishment Report, AERE-R6418, Harwell (1971).

[14] P.W. Cains, S.J. Barnes, Deposition of volatilized ruthenium on stainless steels. J. of Nucl. Mat. 186 (1991) 83-86.

[15] B. Eichler, F. Zude, W. Fan, N. Trautmann, G. Herrmann, Volatilization and deposition of ruthenium oxides. Radiochim. Acta. 56 (1992) 133-140.

[16] G.L. Zimmerman, S.J. Riviello, T.A. Glauser, J.G. Kay, Photochemical decomposition of $\mathrm{RuO}_{4}$. J. of the Amer. Chem. Soc., 94 (1990) 2399-2404.

[17] K.S. Kim, N. Winograd, X-ray Photoelectron Spectroscopic studies. J. of Catal. 35 (1974) 66-72.

[18] T. Sakurai, Y. Hinatsu, A. Takahashi, G. Fujisawa, Adsorption of ruthenium tetroxide on metal surfaces. J. Phys. Chem. 89 (1985) 1892-1896.

[19] C. Mun, L. Cantrel, C. Madic, Study of the ruthenium fission-product behaviour in the containment of a nuclear reactor, in the case of a severe accident occurring in oxidizing conditions. Proc. Nuclear Energy for New Europe. Bled, (2005).

[20] F. Mousset, Electro-volatilisation du ruthénium en milieu nitrique, Thèse Université Paris-VI (2004).

[21] C. Merlet, E.S. Etz, A new quantitative model for multi-layer films in electron probe microanalysis. Proc. Microbeam Analysis, VCH, 203. (1995).

[22] A. Mills, S. Gidding, I. Patel, C. Lauwrence, Thermally activated ruthenium dioxide hydrate. A reproducible, stable oxygen catalyst. J. Chem. Soc. Faraday Trans 1. 83(8) (1987) 2331.

[23] M.A. Henderson, The interaction of water with solid surfaces. , Ed. F.a.r.-S.S.R. (2002) 1-308.

[24] G. Nowogrocki, G. Tridot, Etude de l'acidification des solutions de ruthénates et perruthénates. Bull. Soc. Chim. de France, 124 (1965) 688-690.

[25] H. Debray, A. Joly, Compte rendu des séances de l'académie des sciences, 106 (1888) 328-333.

[26] J.A. Rard, Chemistry and thermodynamics of ruthenium and some of its inorganic compounds and aqueous species. J. of the Amer. Chem. Soc. Chemical Reviews 85(1) (1985) 1-39.

[27] C. Mun, L. Cantrel, C. Madic, Study of $\mathrm{RuO}_{4}$ decomposition in dry and moist air. Accepted for publication, Radiochimica Acta (2007). 


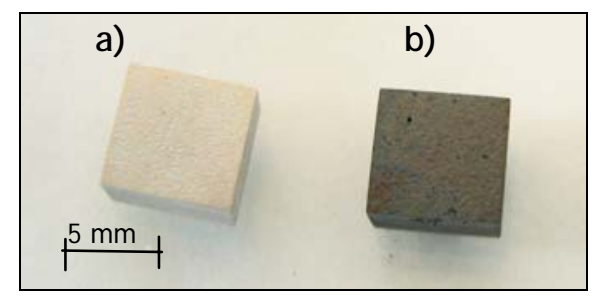

Figure 1: Picture representing stainless steel substrates, before (a), and after (b), $\mathrm{RuO}_{4}(\mathrm{~g})$ deposition.

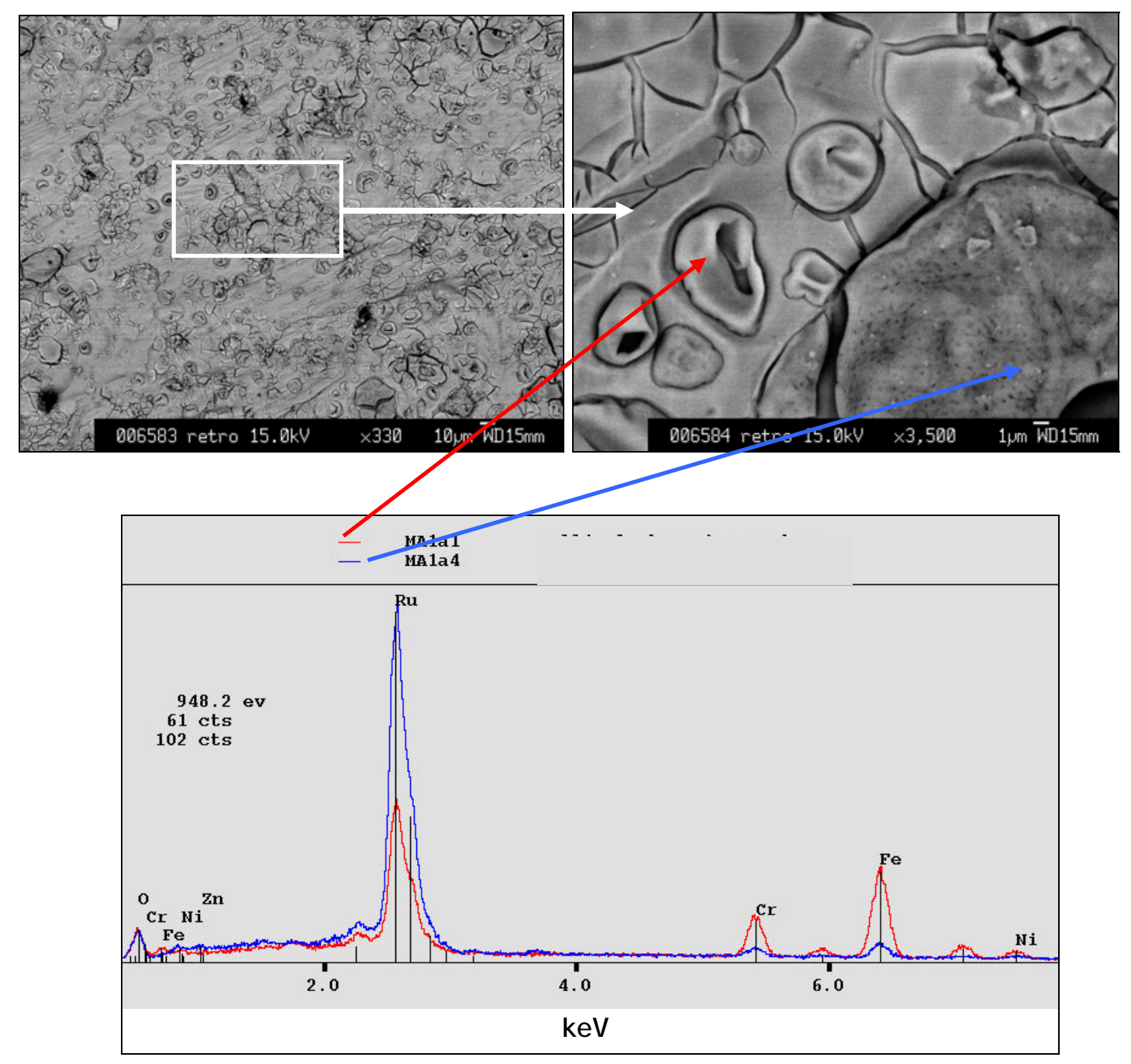

Figure 2: SEM micrographs and EDS spectra of Ru deposited onto stainless steel substrate. 

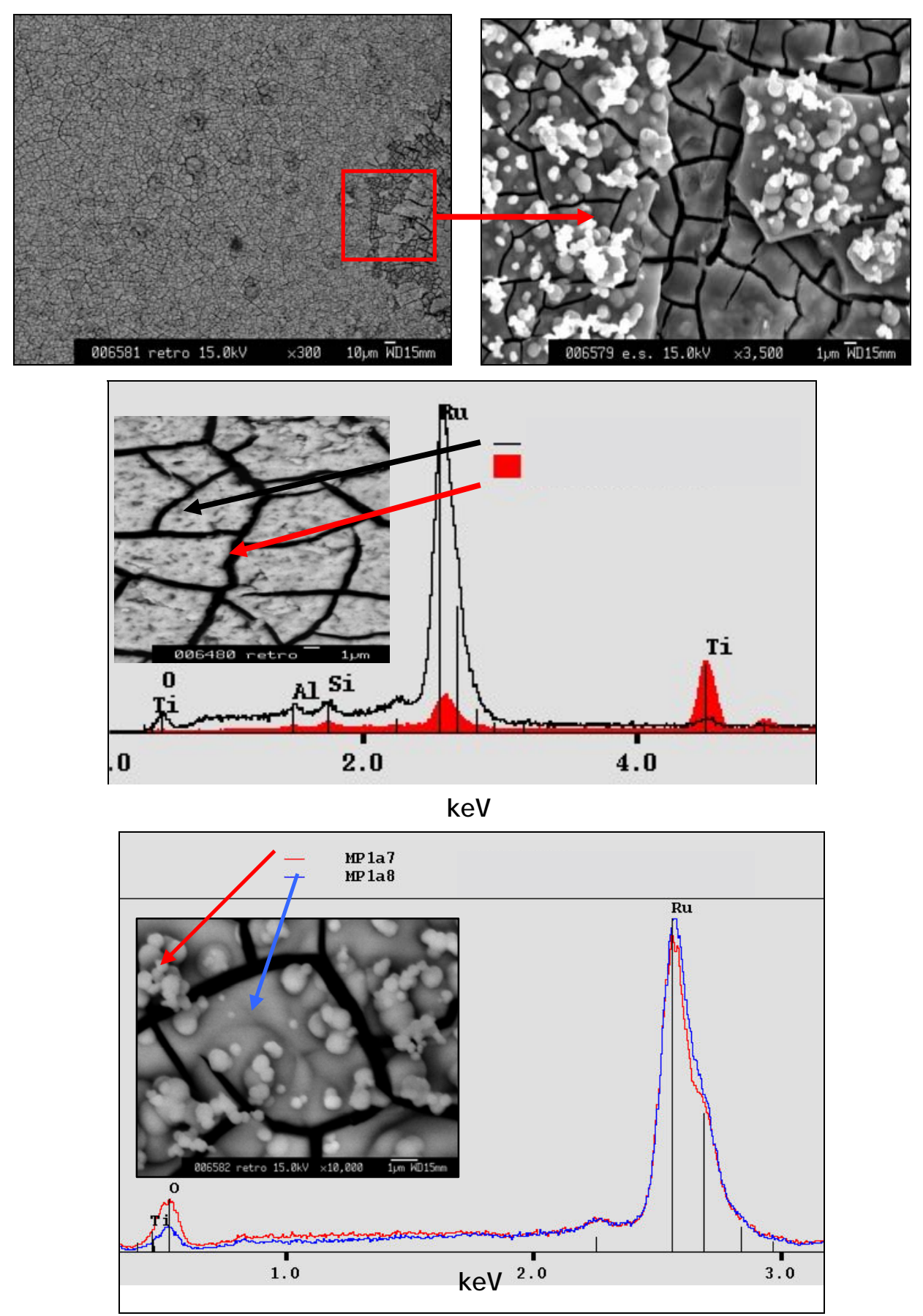

Figure 3: SEM micrographs and EDS spectra of Ru deposited onto painted substrate. 


\begin{tabular}{c|c} 
Tension / Intensity & $I_{\text {deposit }} / I_{\text {substrate }}$ \\
\hline $5 \mathrm{kV} / 20 \mathrm{nA}$ & 0 \\
\hline $7 \mathrm{kV} / 20 \mathrm{nA}$ & 0 \\
\hline $10 \mathrm{kV} / 20 \mathrm{nA}$ & 0.279 \\
\hline $12 \mathrm{kV} / 20 \mathrm{nA}$ & 0.361 \\
\hline $15 \mathrm{kV} / 20 \mathrm{nA}$ & 0.515 \\
\hline $20 \mathrm{kV} / 10 \mathrm{nA}$ & 0.727 \\
\hline $25 \mathrm{kV} / 5 \mathrm{nA}$ & 0.748 \\
\hline $30 \mathrm{kV} / 5 \mathrm{nA}$ & 0.856
\end{tabular}

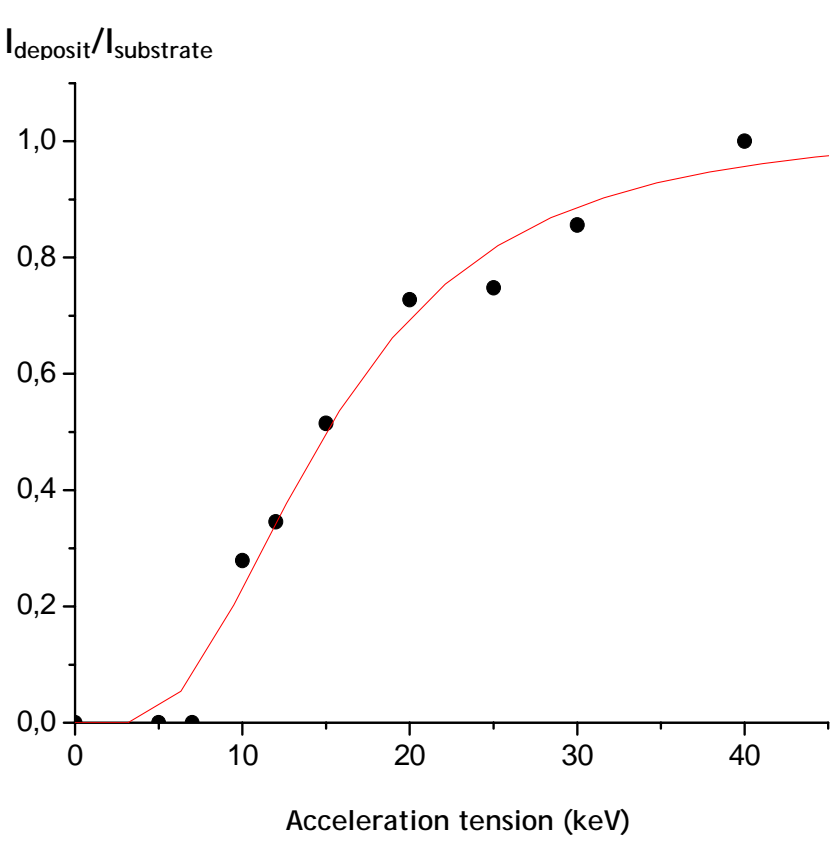

Figure 4: Mean intensities ratios as a function of the acceleration tension.

a)

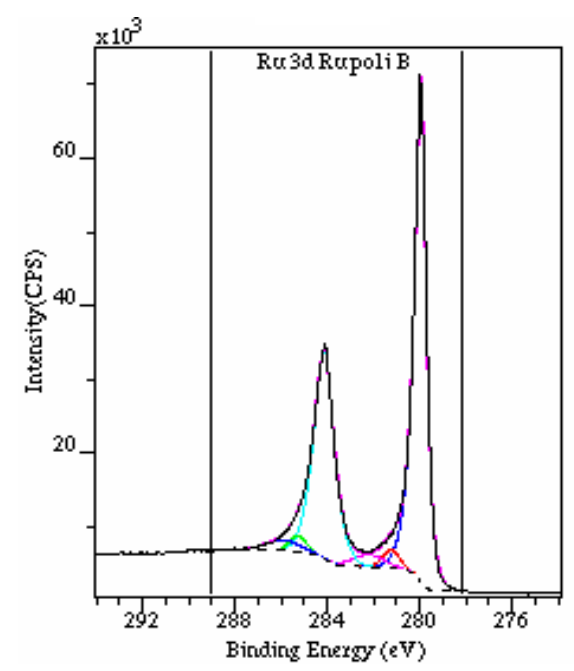

b)

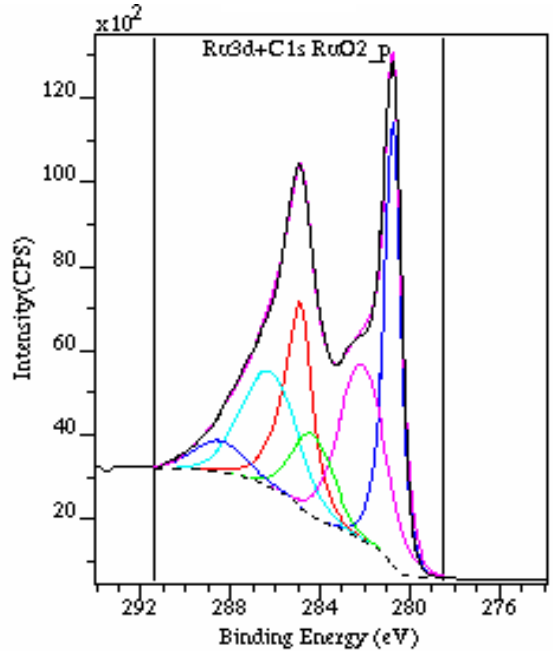

c)

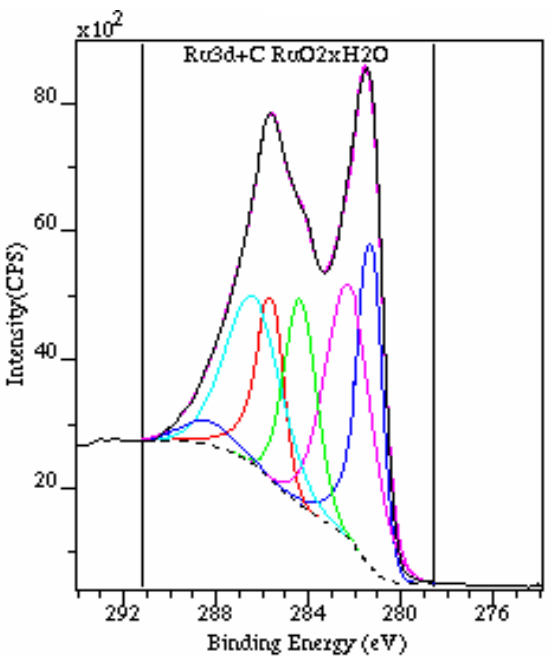

Figure 5: XPS spectra of Ru3d core level lines: on a clean metallic sample (a), of anhydrous $\mathrm{RuO}_{2}$ (b), of hydrated $\mathrm{RuO}_{2}, \mathrm{xH}_{2} \mathrm{O}$ (c). 

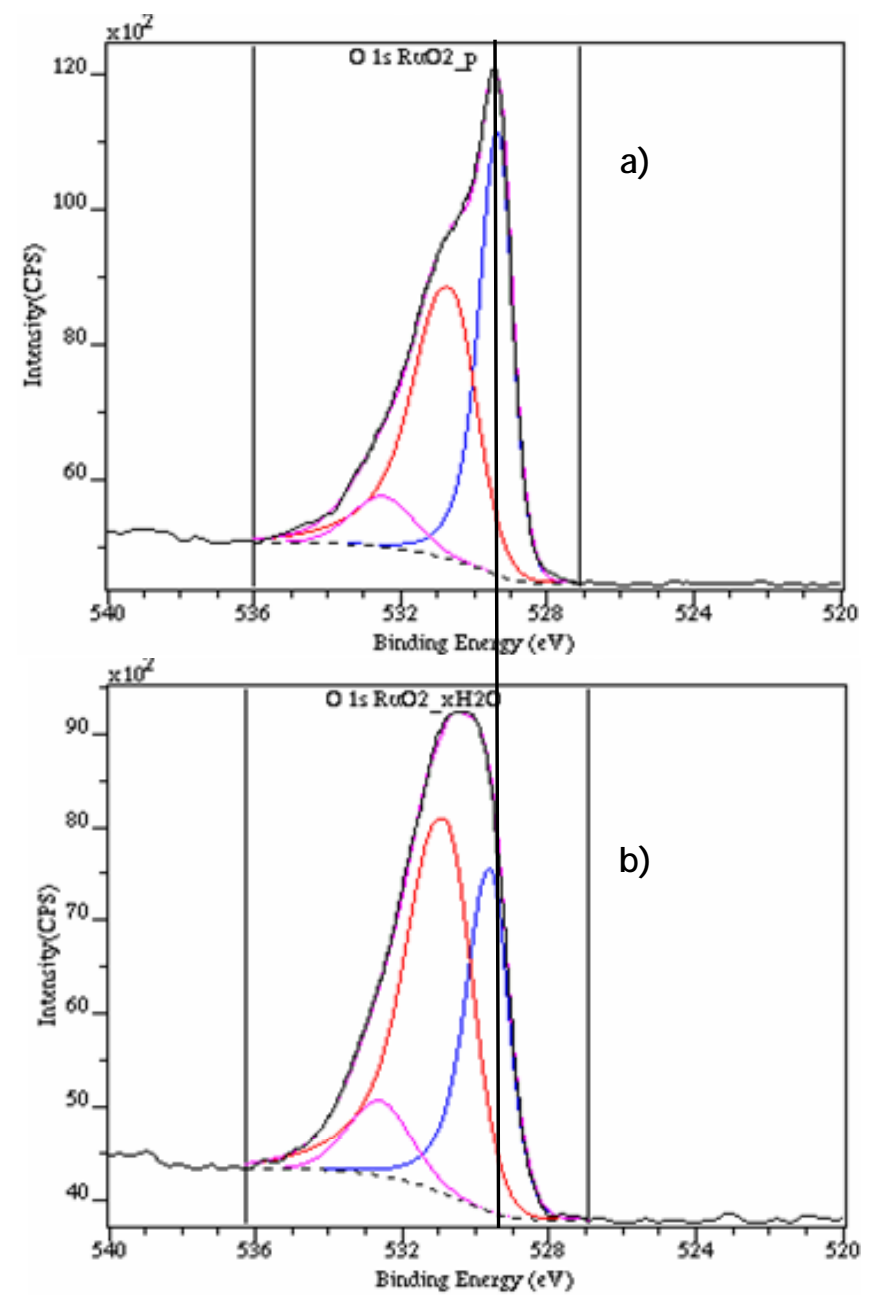

Figure 6: XPS spectra of O1s on anhydrous $\mathrm{RuO}_{2}$ sample (a), and on hydrated $\mathrm{RuO}_{2}, \mathrm{XH}_{2} \mathrm{O}$ sample (b).
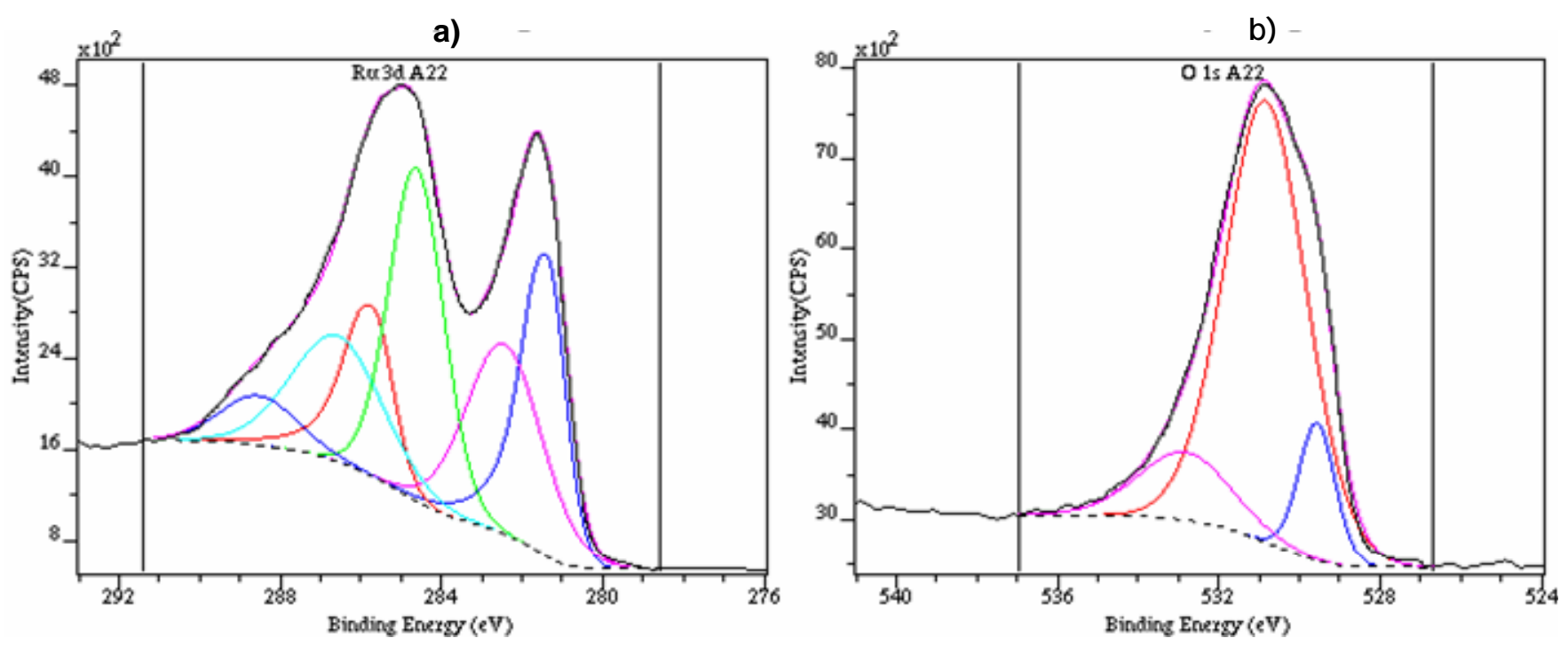

Figure 7: XPS spectra of Ru 3d (a), and O1s (b), of a Ru layer deposited on a piece of stainless steel. 

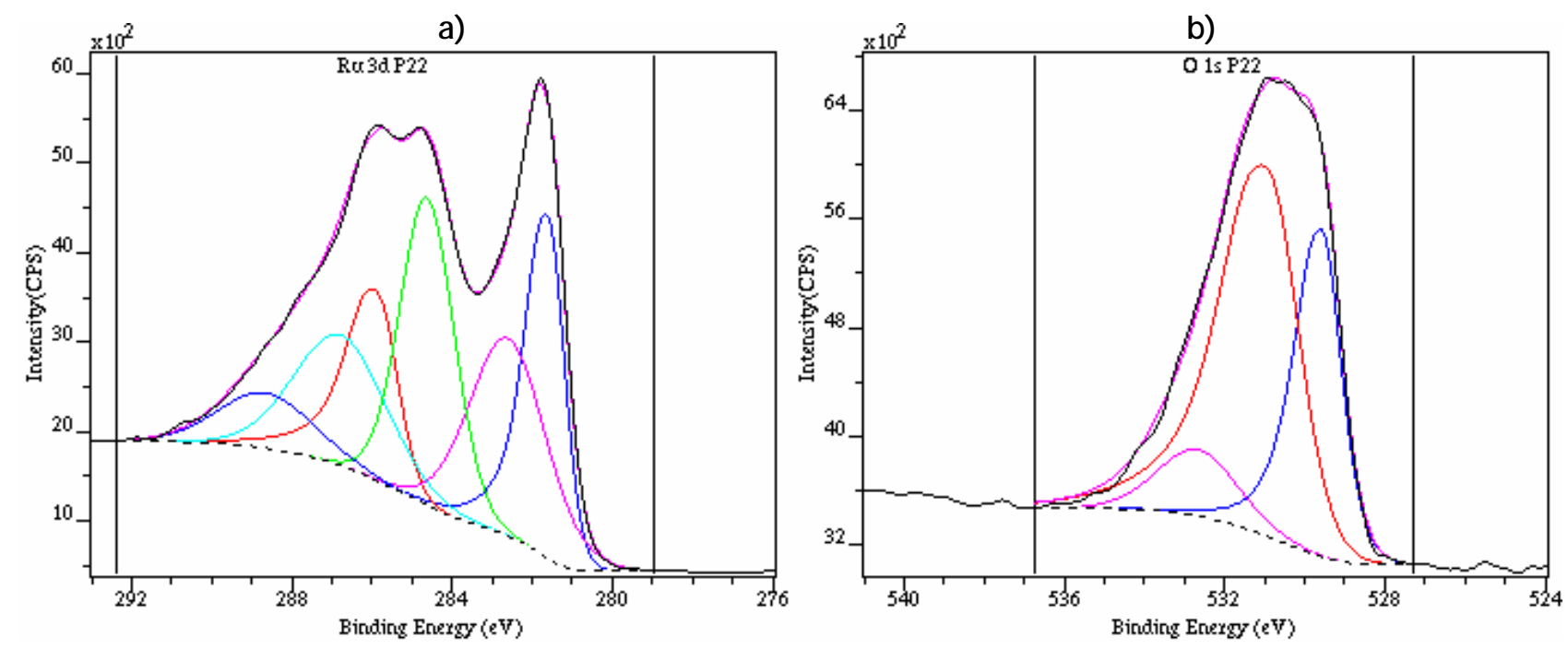

Figure 8: XPS spectra of Ru 3d (a) and O1s (b), of a Ru layer deposited on a painted sample. 